\title{
Increases in Renal $\epsilon$-( $\gamma$-Glutamyl)-Lysine Crosslinks Result from Compartment-Specific Changes in Tissue Transglutaminase in Early Experimental Diabetic Nephropathy: Pathologic Implications
}

\author{
N. James Skill, Martin Griffin, A. Meguid El Nahas, Toru Sanai, John L. Haylor, \\ Marie Fisher, Mathew F. Jamie, Nigel N. Mould, and Timothy S. Johnson \\ Department of Life Sciences (NJS, MG, MF, MFJ, NNM), Nottingham Trent University, Clifton, Nottingham; and \\ Sheffield Kidney Institute (NJS, AMEN, TS, JLH, MF, MFJ, TSJ), Northern General Hospital Trust, Sheffield, United \\ Kingdom
}

SUMMARY: Diabetic nephropathy (DN) is characterized by an early, progressive expansion and sclerosis of the glomerular mesangium leading to glomerulosclerosis. This is associated with parallel fibrosis of the renal interstitium. In experimental renal scarring, the protein cross-linking enzyme, tissue transglutaminase (tTg), is up-regulated and externalized causing an increase in its crosslink product, $\epsilon$-( $\gamma$-glutamyl)-lysine, in the extracellular space. This potentially contributes to the extracellular matrix (ECM) accumulation central to tissue fibrosis by increasing deposition and inhibiting breakdown. We investigated if a similar mechanism may contribute to the ECM expansion characteristic of DN using the rat streptozotocin model over 120 days. Whole kidney $\epsilon-(\gamma$-glutamyl)-lysine (HPLC analysis) was significantly increased from Day $90(+337 \%)$ and peaked at Day $120(+650 \%)(p<$ 0.05). Immunofluorescence showed this increase to be predominantly extracellular in the peritubular interstitial space, but also in individual glomeruli. Total kidney transglutaminase $(\mathrm{Tg})$ was not elevated. However, using a $\mathrm{Tg}$ in situ activity assay, increased Tg was detected in both the extracellular interstitial space and glomeruli by Day 60, with a maximal $53 \%$ increase at Day 120 ( $p$ $<0.05)$. Using a specific anti-tTg antibody, immunohistochemistry showed a similar increase in extracellular enzyme in the interstitium and glomeruli. To biochemically characterize glomerular changes, glomeruli were isolated by selective sieving. In line with whole kidney measurement, there was an increase in glomerular $\epsilon-(\gamma$-glutamyl) lysine $(+361 \%)$; however, in the glomeruli this was associated with increases in Tg activity (+228\%) and tTg antigen by Western blotting $(+215 \%)$. Importantly, the ratio of glomerular $\epsilon$-( $\gamma$-glutamyl) lysine to hydroxyproline increased by 2.2 -fold. In DN, changes in the kidney result in increased translocation of $\mathrm{tTg}$ to the extracellular environment where high $\mathrm{Ca}^{2+}$ and low GTP levels allow its activation. In the tubulointerstitium this is independent of increased tTg production, but dependent in the glomerulus. This leads to excessive ECM cross-linking, contributing to the renal fibrosis characteristic of progressive DN. (Lab Invest 2001, 81:705-716).

$D$ iabetic nephropathy (DN) is a major cause of morbidity and mortality associated with diabetes mellitus (DM). It is rapidly becoming the most common cause of end-stage renal insufficiency worldwide, with an annual cost exceeding $\$ 2$ billion in the United States alone (Alberti and Zimmet, 1998). The number of diabetic patients requiring replacement therapy and the associated costs are expected to rise dramatically with the projected number of people with DM increasing worldwide from 135 million in 1997 to 221 million by 2010 (Amos et al, 1998). The progression of DN is often relentless with hyperglycemia associated with increasing proteinuria and systemic hypertension (Krolewski et al, 1985). Histologically, DN is character-

Received December 7, 2000.

NJ Skill and M Griffin are equal first authors. This study was supported by a grant from the British Diabetic Association.

Address reprint requests to: Dr. Timothy Johnson, The Sheffield Kidney Institute, Northern General Hospital Trust, Herries Road, Sheffield S5 7AU, United Kingdom. E-mail: T.Johnson@sheffield.ac.uk ized by a progressive expansion of the extracellular matrix $(E C M)$ within the glomeruli and the interstitium (Defronzo, 1995) leading to glomerulosclerosis and tubulointerstitial fibrosis, respectively (Mauer et al, 1984). Although considerable advances have been achieved over the last two decades in our understanding of the pathophysiology of DN, many questions remain unanswered regarding the progressive fibrosis of diabetic kidneys. In particular, the mechanism underlying the expansion of the mesangial matrix remains poorly defined. Although some observations have suggested increased ECM synthesis to be the major cause, this was not universally found (Fukui et al, 1992; Suzuki et al, 1997). It has been suggested that there are qualitative changes in the ECM leading to alterations in the glomerular basement membrane (GBM) proteoglycan content, thus affecting the GBM charge (Wayl et al, 1982). Others have suggested a decrease in the diabetic kidney collagenolytic activity leading to decreased ECM breakdown and tissue accumulation (Lupia et al, 1999). 
In two recent studies using a rat subtotal nephrectomy model of renal scarring, we have highlighted changes in both the expression and the localization of an enzyme called tissue transglutaminase (tTg). tTg belongs to a group of calcium-dependent enzymes capable of catalyzing the post-translational modification of proteins through the formation of $\epsilon-(\gamma-$ glutamyl)-lysine dipeptide bonds (Lorand and Conrad, 1984). Covalent crosslinks using $\epsilon-(\gamma$-glutamyl)-lysine bonds are stable and resistant to enzymatic, chemical, and mechanical disruption (Folk and Finlayson, 1977). Endopeptidases capable of hydrolyzing the $\epsilon-(\gamma-$ glutamyl)-lysine crosslink have not been described in vertebrates (Fesus et al, 1989). The transglutaminase (Tg) enzyme family consists of at least four further groups of enzymes, including factor XIIla and keratinocyte Tg (Griffin and Smethurst, 1996). Perturbations in tTg have been noted in diseases including Alzheimer's, carcinogenesis, and celiac disease (Dudek and Johnson, 1993; Knight et al, 1991; Molberg et al, 2000). However, there are increasing reports of its involvement in fibrotic conditions including, heart (Small et al, 1999), liver (Mirza et al, 1997), lung (Griffin et al, 1979), and renal fibrosis (Johnson et al, 1997, 1999). tTg has also been linked to cell-matrix adhesion (Verderio et al, 1998) and cellular response to stress, as well as to apoptosis (Fesus et al, 1989; Mirza et al, 1997). The enzyme is also involved in the matrix storage and activation of transforming growth factor (TGF)- $\beta 1$ (Nunes et al, 1997) and can act as a G protein subunit mediating the transduction of hormonal signals (Im et al, 1997).

During experimental renal scarring (renal ablation) there is an mRNA-dependent increase in tTg (Johnson et al, 1999), particularly within the proximal tubular epithelial cells, that results in increased translocation of tTg from the intracellular to the pericellular environment. Increased $\epsilon$-( $\gamma$-glutamyl)-lysine crosslink is found in both intracellular proteins and those of the surrounding peritubular ECM in remnant kidneys (Johnson et al, 1997, 1999). tTg action may therefore contribute toward renal fibrosis through at least three pathways. First, intracellular increases in $\epsilon-(\gamma-$ glutamyl)-lysine indicate extensive cytosolic protein cross-linking that is incompatible with cell viability. These cells may therefore die through a Tg-mediated death pathway independent of both apoptosis and necrosis (Griffin and Verderio 2000; Johnson et al, 1998; Verderio et al, 1998). This may well contribute to the tubular cell deletion seen in progressive renal scarring. Second, extracellular cross-linking of the ECM; fibronectin (Lorand et al, 1988), collagens I, III, IV (Bowness et al, 1987), and IX (Kleman et al, 1995), laminin, and nidogen (Aeschlimann and Paulsson, 1991) are tTg substrates. Such cross-linking of the ECM components could contribute to increased ECM deposition given the ability of tTg to crosslink collagen fibrils (even in the absence of lysyl oxidase) (Kleman et al, 1995) and also stabilize the ECM by conferring a resistance to proteolytic enzymes (Johnson et al, 1999; Verderio et al, 1999). Finally, the requirement of tTg for the matrix storage (Verderio et al, 1999) and subsequent activation of the profibrogenic growth factor TGF- $\beta 1$ could potentiate disease progression (Nunes et al, 1997).

In this study, we aim to define the role of tTg in the development of experimental DN after the administration of streptozotocin (STZ) to rats. First we assessed if there were changes in the $\epsilon$-( $\gamma$-glutamyl)-lysine crosslink in the diabetic kidney and then determined where these occur by immunofluorescence. Second, we investigated the reason for these changes by measuring any changes in both the level and location of renal $\mathrm{Tg}$, to see if these could be ascribed to tTg. Finally, using isolated glomeruli, we assessed changes specifically within the glomeruli, where we also investigated if changes in cross-linking cause qualitative changes to glomerular ECM proteins.

\section{Results}

\section{General Observations}

Forty-eight hours after STZ injection, hyperglycemia was induced in all but three animals that received a successful injection of STZ (Table 1). Nondiabetic animals receiving STZ were used as controls for the effect of STZ on the kidney. Hyperglycemia resulted in a significant reduction of rat body weight $(p<0.01)$ and increase in fractional kidney weight at all time points $(p<0.01)$ (Table 1). Renal function was altered from as early as Day 7. Proteinuria was progressive over the duration of the experiment, whereas serum creatinine remained within the normal range. Point counting of Masson's trichrome-stained sections showed a progressive increase in collagen staining in the glomerular and tubulointerstitial compartments that was apparent by Day 30 and 60, respectively. However, this did not reach significance in both compartments until Day 90 (glomerulus: $4.1 \pm 0.6 \%$ (control) versus $8.7 \pm 2.8 \%$ (DN) $p<0.01$ ); tubulointerstitium: $4.0 \pm 0.8 \%$ (control) versus $10.2 \pm 1.7 \%$ (DN) $p$ $<0.01$ ). Masson's trichrome-stained sections from hyperglycemic animals also showed substantial tubular cell vacuolation, particularly in distal tubular and collecting duct cells. This was most evident on Days 90 and 120. Animals receiving STZ, but not becoming diabetic, showed no change in renal function (Table 1), Masson's trichrome staining, or tubular vacuolation.

\section{Measurements in Whole Kidney}

Whole Kidney $\epsilon-(\gamma$-Glutamyl)-Lysine Levels. Biochemical assessment of whole kidney $\epsilon$-( $\gamma$-glutamyl)lysine by exhaustive proteolytic digestion and ion exchange chromatography showed the level of the dipeptide remained constant in control kidneys throughout the experimental period. In contrast, the $\epsilon$-( $\gamma$-glutamyl)-lysine crosslink concentrations in kidneys from hyperglycemic rats showed a small nonstatistically significant increase from Day 7 to Day 60, with a rapid and significant increase at Day 90 $(+337 \%)$ and Day $120(+650 \%)(p<0.01)$ (Fig. 1). At 120 days, in nondiabetic STZ-treated animals there 
Table 1. Terminal Body and Kidney Weights, Fractional Kidney Weight, Serum Creatinine, Blood Glucose, and Proteinuria in Control and STZ Animals ${ }^{a}$

\begin{tabular}{|c|c|c|c|c|c|c|c|}
\hline $\begin{array}{l}\text { Time } \\
\text { period } \\
\text { (d) }\end{array}$ & & $\begin{array}{l}\text { Terminal } \\
\text { body weight } \\
\text { (g) }\end{array}$ & $\begin{array}{l}\text { Terminal } \\
\text { kidney weight } \\
\text { (mg) }\end{array}$ & $\begin{array}{l}\text { Fractional } \\
\text { kidney } \\
\text { weight }\end{array}$ & $\begin{array}{l}\text { Serum } \\
\text { creatinine } \\
(\mu \mathrm{M})\end{array}$ & $\begin{array}{c}\text { Serum } \\
\text { glucose }(\mathrm{mM})\end{array}$ & $\begin{array}{l}\text { Proteinuria } \\
(\mathrm{mg} / 24 \mathrm{hr})\end{array}$ \\
\hline \multirow[t]{2}{*}{7} & Control & $437 \pm 24$ & $1.2 \pm 0.1$ & $2.6 \pm 0.2$ & $52.7 \pm 9.1$ & $8.5 \pm 0.2$ & $14.6 \pm 4.6$ \\
\hline & STZ & $376 \pm 10^{*}$ & $1.4 \pm 0.1^{*}$ & $3.8 \pm 0.1^{*}$ & $42.2 \pm 8.9$ & $28.3 \pm 1.4^{\star *}$ & $52.8 \pm 9.5^{\star \star}$ \\
\hline \multirow[t]{2}{*}{14} & Control & $424 \pm 12$ & $1.1 \pm 0.1$ & $2.7 \pm 0.2$ & $38.0 \pm 4.0$ & $12.5 \pm 1.8$ & $16.8 \pm 2.1$ \\
\hline & STZ & $354 \pm 23^{\text {** }}$ & $1.5 \pm 0.2^{\star *}$ & $4.3 \pm 0.4^{\star *}$ & $34.8 \pm 3.4$ & $35.4 \pm 3.7^{\star *}$ & $92.8 \pm 3.6^{\star *}$ \\
\hline \multirow[t]{2}{*}{30} & Control & $520 \pm 10$ & $1.2 \pm 0.1$ & $2.6 \pm 0.2$ & $47.3 \pm 7.1$ & $10.1 \pm 1.1$ & $14.7 \pm 1.1$ \\
\hline & STZ & $359 \pm 46^{\star *}$ & $1.6 \pm 0.1^{\star *}$ & $5.1 \pm 0.2^{\star \star}$ & $40.6 \pm 4.3$ & $25.9 \pm 2.9^{\star *}$ & $83.3 \pm 21.0^{\text {** }}$ \\
\hline \multirow[t]{2}{*}{60} & Control & $525 \pm 14$ & $1.3 \pm 0.1$ & $2.6 \pm 0.2$ & $37.2 \pm 2.6$ & $8.6 \pm 0.5$ & $13.2 \pm 0.2$ \\
\hline & STZ & $359 \pm 47^{\star *}$ & $1.8 \pm 0.2^{\star *}$ & $5.1 \pm 0.2^{\star *}$ & $32.0 \pm 2.0$ & $34.5 \pm 1.3^{* *}$ & $124 \pm 28.0^{\text {** }}$ \\
\hline \multirow[t]{2}{*}{90} & Control & $485 \pm 26$ & $1.1 \pm 0.1$ & $2.2 \pm 0.9$ & $44.8 \pm 0.8$ & $11.6 \pm 0.5$ & $15.8 \pm 3.0$ \\
\hline & STZ & $352 \pm 66^{\star *}$ & $1.5 \pm 0.1$ & $4.5 \pm 0.7^{*}$ & $42.2 \pm 1.3$ & $31.4 \pm 6.2^{* *}$ & $179.0 \pm 22.0^{*}$ \\
\hline \multirow[t]{3}{*}{120} & Control & $520 \pm 24$ & $1.4 \pm 0.1$ & $5.1 \pm 0.8$ & $35.4 \pm 3.9$ & $9.2 \pm 0.8$ & $18.3 \pm 3.0$ \\
\hline & STZ & $314 \pm 30^{\star * *}$ & $1.6 \pm 0.2$ & $9.2 \pm 1.3^{* *}$ & $30.0 \pm 2.0$ & $28.1 \pm 0.8^{\star *}$ & $168.0 \pm 30.0^{* *}$ \\
\hline & $\begin{array}{l}\text { Nondiabetic } \\
\text { STZ }\end{array}$ & $518 \pm 44$ & $1.4 \pm 0.6$ & $5.1 \pm 0.3$ & $36.6 \pm 4.1$ & $10.9 \pm 0.9$ & $17.2 \pm 3.1$ \\
\hline
\end{tabular}

STZ, streptozotocin.

${ }^{a}$ Data represent mean \pm SEM.

${ }^{\star} p<.05$, STZ compared with controls; ${ }^{\star \star} p<.01$, STZ compared with controls.

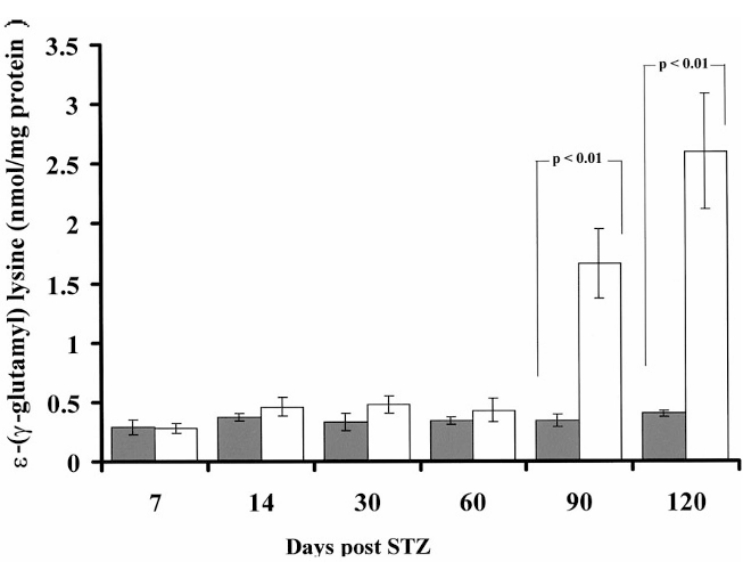

Figure 1.

Renal $\epsilon$-( $\gamma$-glutamyl)-lysine crosslink measurements for control (dark bars) and STZ (white bars) kidney homogenates. $\epsilon$-( $\gamma$-glutamyl)-lysine levels were determined by exhaustive proteolytic digestion and cation exchange chromatography. Data represent mean crosslink values ( $\mathrm{nmol} / \mathrm{mg}$ protein) $\pm \operatorname{SEM}(n=$ 5-6 per group).

was no difference in the $\epsilon$-( $\gamma$-glutamyl)-lysine crosslink levels from those in the control animals.

Renal Distribution of $\epsilon$-( $\gamma$-Glutamyl)-Lysine Crosslink. Staining for the $\epsilon-(\gamma$-glutamyl)-lysine crosslink in control rats was minimal throughout the time course (Fig. 2, A and E). There was some weak and intermittent staining within the tubulointerstitial space and in occasional glomeruli. Intracellular staining was noted in a few tubular cells. In kidneys from hyperglycemic animals, $\epsilon-(\gamma$-glutamyl)-lysine staining was similar to that in controls until Days 90 and 120 when large increases in staining were clearly visible (Fig. 2, B to D, F to $\mathrm{H}$ ). The magnitude of these changes became more evident when autofluorescence was omitted by using emissions at $650 \mathrm{~nm}$ only (Fig. 2, $\mathrm{E}$ to $\mathrm{H}$ ). This increase was predominantly localized to discrete areas of the tubulointerstitial space and to glomeruli (Fig. 2, C to D, G to H). Staining was particularly evident around tubules that had undergone vacuolation that do not exhibit autofluorescence at $530 \mathrm{~nm}$ (Fig. 2, B and F). There was a great variation in staining between glomeruli, with most of the increase in glomerular staining concentrated in about a fifth of the glomeruli. Specific localization to any glomerular structures was not possible due to the use of cryostat tissue, although the staining suggested a distribution along the GBM (Fig. 2D). Semiquantitation of glomeruli and tubulointerstitial staining using the emission intensity at $665 \mathrm{~nm}$ for Cy5 (Fig. 3) showed a similar increase in $\epsilon$-( $\gamma$-glutamyl)-lysine crosslink to that determined biochemically (Fig. 1). Little increase in emissions was seen until Day 120 when a $319 \%$ increase over control was measured in STZ-treated rats $(p<0.05)$. Replacement of the primary antibody with mouse nonimmune IgG showed no significant staining (data not shown).

Whole Kidney Tg Activity. Measurement of total Tg protein in renal homogenates by activity assay showed that in control tissue there was a gradual, but not significant, decrease with time. In the kidneys from hyperglycemic rats at all time points there was a surprising trend toward a reduction in Tg; however, this was only statistically significant on Days 7 and 120 with values reduced by approximately $25 \%$ (Fig. 4).

Renal In Situ Tg Activity. In control kidneys, detectable activity measured by incorporation of the primary amine substrate fluorescein cadaverine was stable throughout the time course. Staining intensity was both mild and dispersed, with activity seen predominantly around blood vessels, but also occasionally in glomeruli. Activity within the tubulointerstitial space was not readily detectable. Control staining in glomeruli was not visible using the optimal photomultiplier 

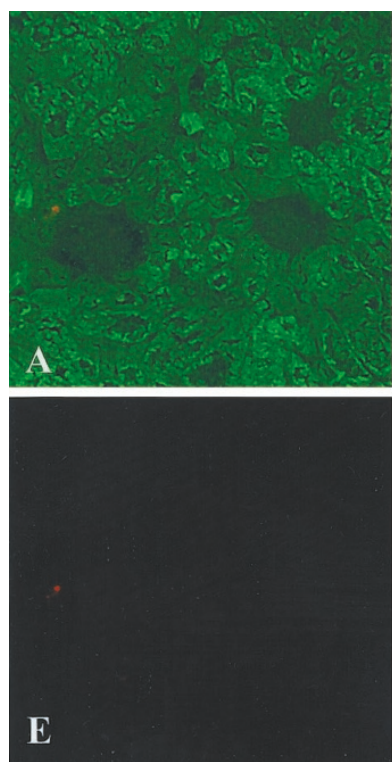
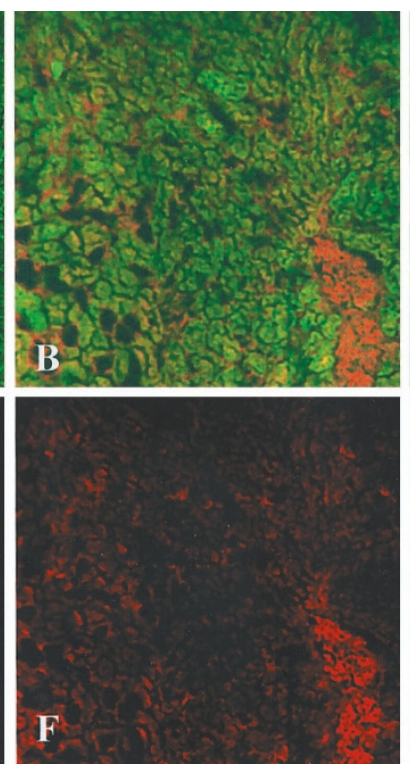
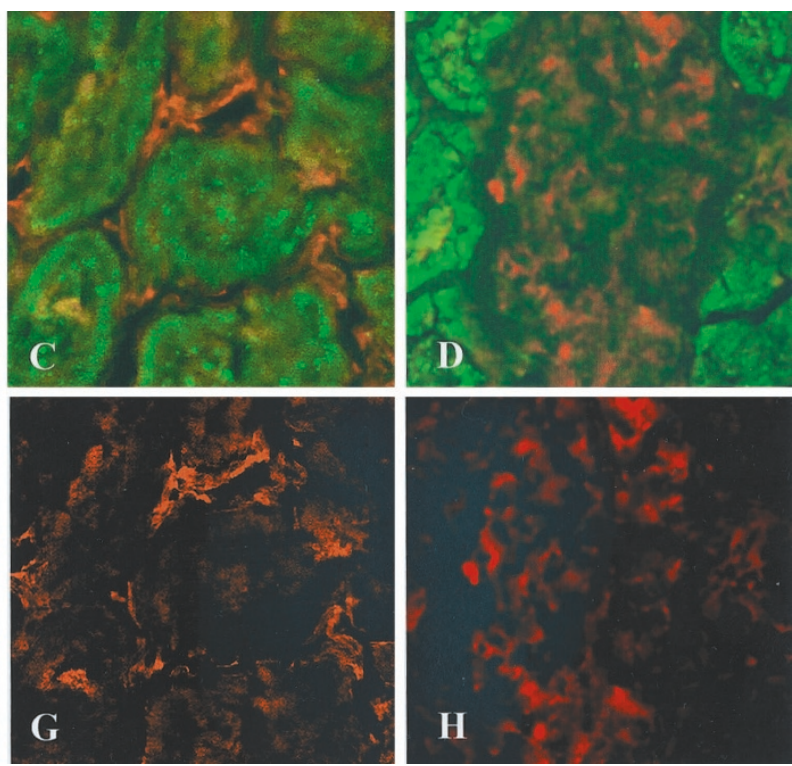

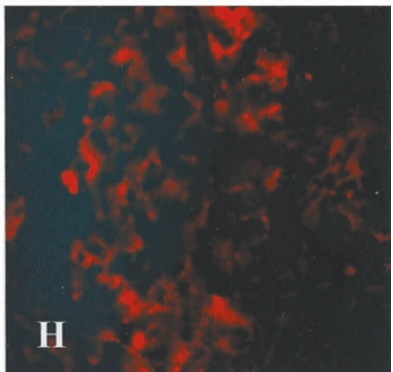

Figure 2.

Representative sections from 120-day control ( $A$ and $E$ ) and STZ kidneys ( $B$ to $D$ and $F$ to $H$ ) immunoprobed for $\epsilon$-( $\gamma$-glutamyl)-lysine (red). A to D, autofluorescence at $530 \mathrm{~nm}$ (green) and Cy5 fluorochrome at $665 \mathrm{~nm}$ (red). E to $\mathrm{H}$, Cy5 fluorochrome only. A to $B$ and $E$ to $F$, original magnification $\times 100$; $C$ to $D$ and $G$ to $H$, original magnification $\times 400$.

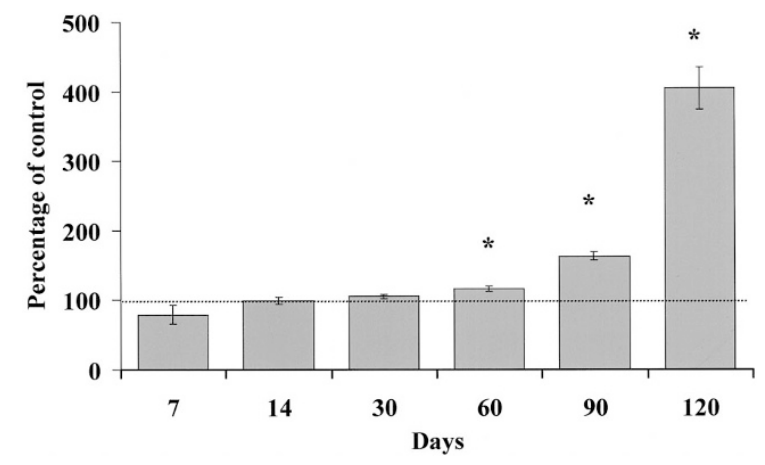

Figure 3.

Semiquantitation of Cy5 emissions at $665 \mathrm{~nm}$ from cryostat sections immunoprobed for $\epsilon$-( $\gamma$-glutamyl)-lysine. Values are expressed as emissions (mV) $\mu \mathrm{m}^{2}$ ) from hyperglycemic renal cryostat sections as a percentage of the time-matched control mean. $n=4-6$ per group, * indicates $p<0.05$. At least 10 fields per section were analyzed.

tube settings to view DN sections (Fig. 5, A and E). In STZ-treated animals, there was a visible increase in extracellular $\mathrm{tTg}$ activity in the tubulointerstitium by Day 60. This was concentrated around tubules displaying vacuolation (Fig. 5, B, D, F, and $\mathrm{H}$ ), paralleling the same increases in the $\epsilon$-( $\gamma$-glutamyl)-lysine crosslink found in those areas. Elevated $\mathrm{Tg}$ activity was also seen within the glomeruli (Fig. 5, C and G), once again paralleling the maximum increases in protein crosslink. Because of poor morphology it was not possible to localize the staining to any specific ECM protein structure. This was exacerbated by the inability to clearly see staining when combined with tissue autofluorescence emissions at $530 \mathrm{~nm}$ (Fig. 5, A to D). However, it appeared to be consistent with both the staining for $\epsilon$-( $\gamma$-glutamyl)-lysine and tTg in terms of location and time of appearance. Semiquantitation of the overall Cy5 emission at $655 \mathrm{~nm}$, from multiple

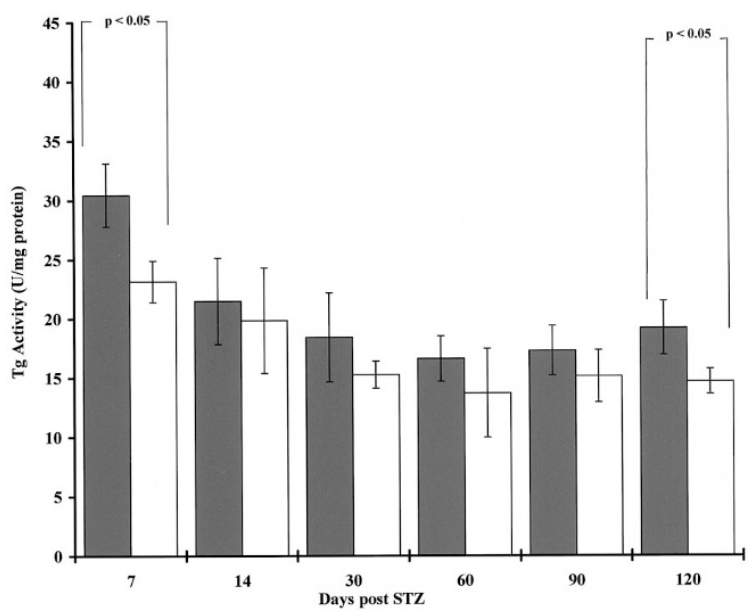

Figure 4.

Renal transglutaminase $(\mathrm{Tg})$ level determined using the enzymatic incorporation of $\left[{ }^{14} \mathrm{C}\right]$ putrescine into $\mathrm{N}, \mathrm{N}$ '-dimethylcasein in homogenates from control (grey bars) and hyperglycemic (white bars) animals. Data represent mean $\mathrm{Tg}$ activity $(\mathrm{U} / \mathrm{mg}$ protein) $\pm \operatorname{SEM}(n=4-6)$. One unit of activity $=1 \mathrm{nmol}$ putrescine incorporated per hour at $37^{\circ} \mathrm{C}$.

fields of view $(n=10)$, showed a steady activity in control kidneys, whereas in kidneys from hyperglycemic animals, increases were detectable by Day 60 , were significant by Day 90, and peaked at Day 120 $(+53 \%, p<0.05)$ (Fig. 6). The preincubation of sections with the $\mathrm{Tg}$ antagonist cystamine inhibited incorporation of fluorescein cadaverine and reduced Cy5 emissions (Fig. 5, I to L).

Distribution of Renal $\mathrm{tTg}$. Induction of diabetes in animals resulted in a redistribution of $\mathrm{tTg}$ within the diabetic kidney, as shown by immunofluorescence studies for insoluble tTg (attached to substrate) (Fig. 7). In control kidneys it was difficult to observe any staining, with the exception of some occasional stain- 

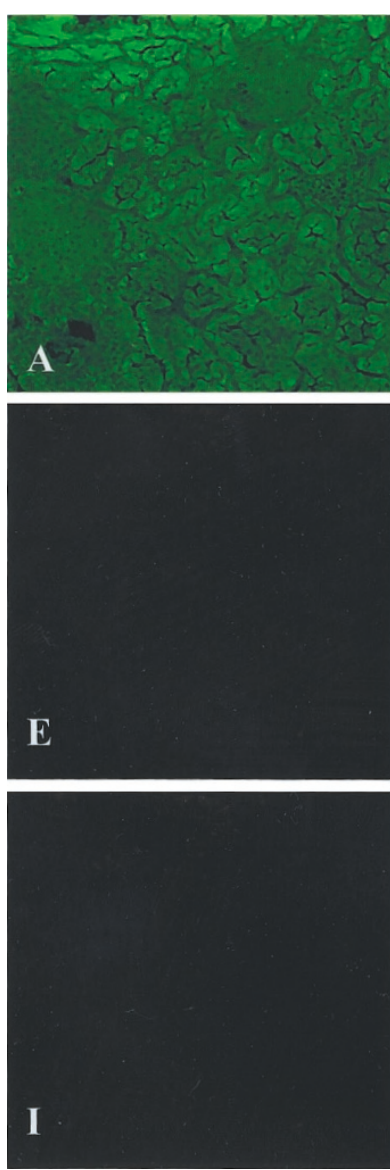
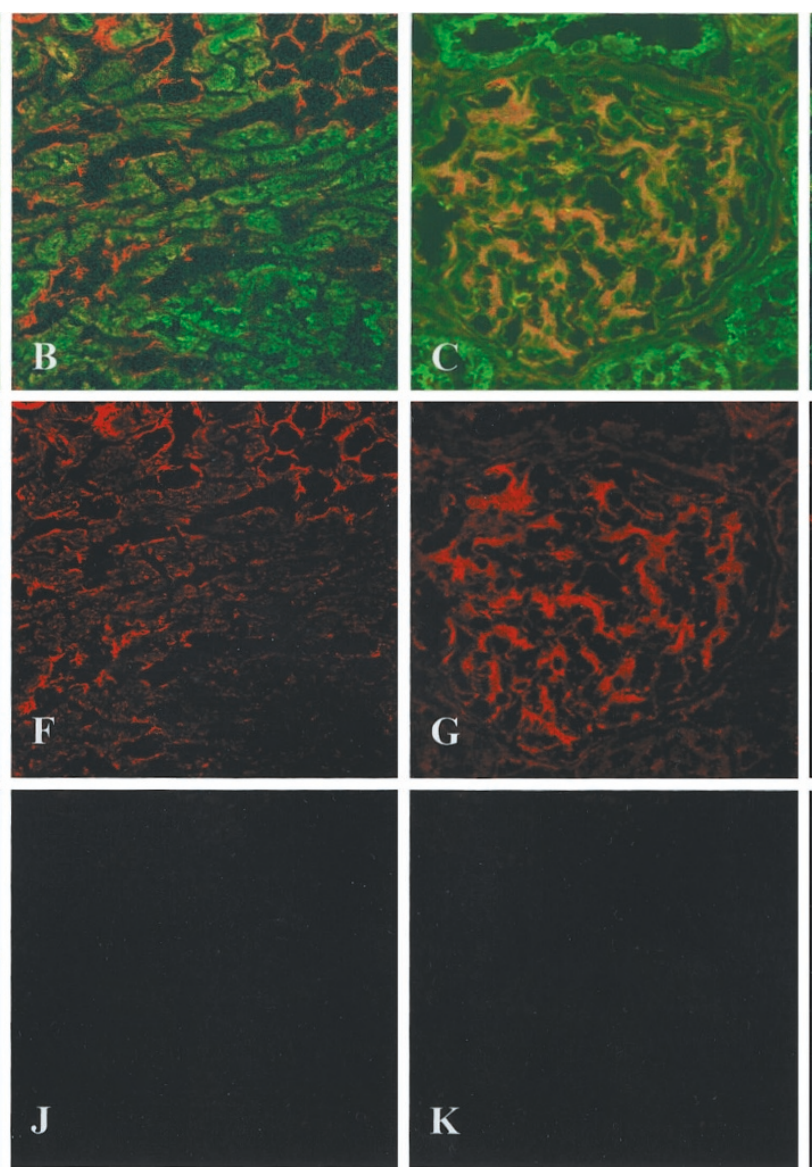
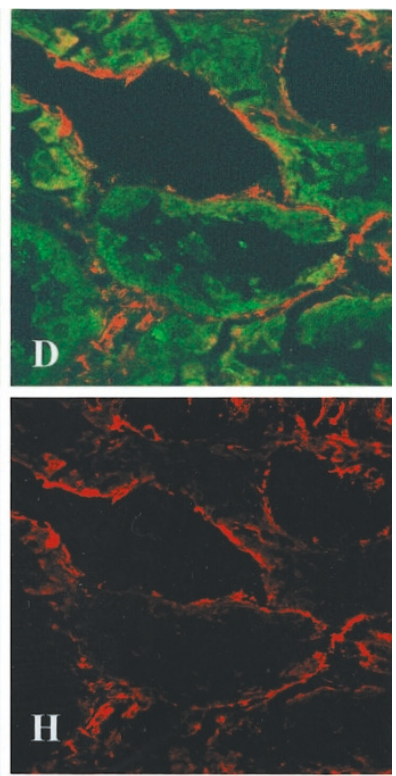

Figure 5.

Representative photomicrographs from 120-day control (A, E, and I) and hyperglycemic kidneys ( $B$ to $D, F$ to $H$, and $J$ to $L$ ) subjected to in situ activity assay for $\mathrm{Tg}$ (red). A to D, fluorescent emissions at both $665 \mathrm{~nm}$ (Cy5) and $530 \mathrm{~nm}$ (tissue autofluorescence). E to L, fluorescent emissions at $665 \mathrm{~nm}$ (Cy5) only. I to L, sequential sections pretreated with the $\mathrm{Tg}$ antagonist cystamine. $\mathrm{A}, \mathrm{B}, \mathrm{E}, \mathrm{F}, \mathrm{I}$, and $\mathrm{J}$, original magnification $\times 100 ; \mathrm{C}, \mathrm{D}, \mathrm{G}, \mathrm{H}, \mathrm{K}$, and L, original magnification $\times 400$.

ing in the tubulointerstitial space and the odd glomeruli, especially at settings optimized for staining in DN (Fig. 7, A and E). In contrast, insoluble tTg was detectable in kidneys of diabetic rats early in the experimental time course (Day 30) that became both more intense and more widespread by Days 90 and 120. In keeping with the observations shown for $\epsilon$-( $\gamma$-glutamyl)-lysine crosslink and in situ activity data, increased $\mathrm{tTg}$ staining was predominantly within the tubulointerstitial space (Fig. 7, B to C, F to G) and especially around tubules with pronounced vacuolation that did not autofluoresce (Fig. 7, B, F, and I to L). Significant increases in staining were also seen within diabetic glomeruli (Fig. 7, D and H). Both the distribution and timing of this staining were consistent with that observed for $\epsilon-(\gamma$-glutamyl)-lysine (Fig. 2). Semiquantitation of the overall immunofluorescence, from multiple fields of view $(n=10)$ at $655 \mathrm{~nm}$, showed an early and progressive increase in staining in kidneys. This was significant by Day 90 with a 2-fold increase, giving a maximum increase of 3.5 -fold by Day 120 compared with the time-matched controls $(p<0.05)$ (Fig. 8). The replacement of the primary antibody with mouse nonimmune $\mathrm{lg} G$ showed no significant staining (data not shown).
$T g, \epsilon-(\gamma$-Glutamyl)-Lysine, and Hydroxyproline in Isolated Glomeruli. The glomeruli constitute less than $5 \%$ of the renal cell mass, and thus, analysis of renal homogenates reflects tubulointerstitial changes. To specifically characterize glomerular biochemistry we isolated glomeruli by selective sieving. Samples of recovered glomeruli when viewed by light microscopy showed minimal levels of tubular fragment contamination. Any preparation showing more than one tubular fragment per 10 intact glomeruli were re-sieved.

Measurement of $\epsilon$-( $\gamma$-glutamyl)-lysine showed a significant $361 \%$ increase (Table 2). This was accompanied by a $228 \%$ increase in glomerular Tg activity, with a similar $215 \%$ increase in glomerular tTg antigen by Western blot analysis (Table 2). There was a significant $160 \%$ increase in glomerular hydroxyproline levels, generating a 2.2-fold increase in the ratio of glomerular $\epsilon$-( $\gamma$-glutamyl)-lysine to hydroxyproline.

\section{Discussion}

The progression of DN is associated with the progressive sclerosis of the glomeruli and the concomitant fibrosis of the renal interstitium. Although the experimental model we used in this study (STZ-induced 


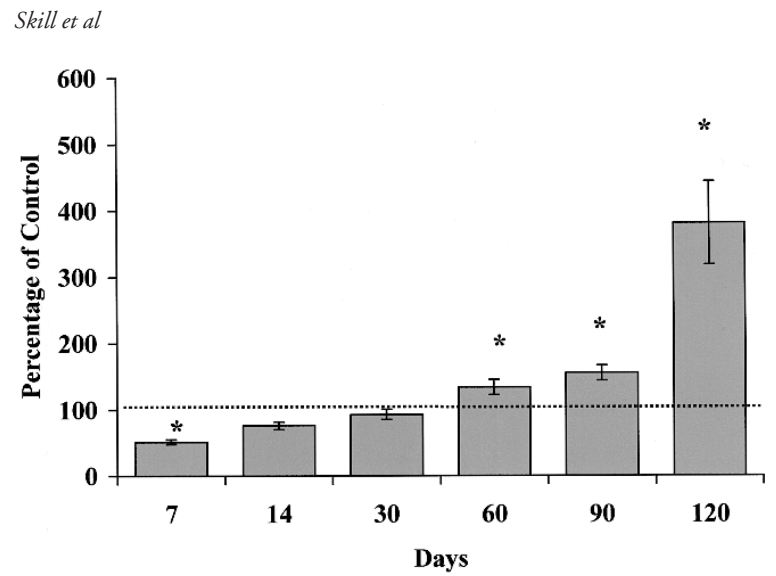

Figure 6.

Semiquantitation of Cy5 emissions at $655 \mathrm{~nm}$ from cryostat sections subjected to in situ $\mathrm{Tg}$ activity assay. Values are expressed as emissions from hyperglycemic renal cryostat sections as a percentage of the time-matched control mean. $n=4-6$ per group, ${ }^{*}$ indicates $p<0.05$. At least 10 fields per section were analyzed.

diabetes) is not fully representative of DN in humans (Phillips et al, 1999; Rasch, 1988), it provides a method of studying preclinical developmental DN changes. It is, at worst, a model of sustained hyperglycemia and, at best, displays some of the histologic changes that take place in human DN. In particular, an expansion of the glomerular mesangium is known to take place in rats with sustained hyperglycemia, with an increased deposition of ECM in the glomeruli and the tubulointerstitium (Mauer et al, 1984; Rasch, 1988; Ziyadeh and Goldfarb, 1991). The mechanisms underlying these changes and similar ones taking place in human diabetic kidneys are not understood fully.

In this study, we demonstrate an increase in total renal $\epsilon$-( $\gamma$-glutamyl)-lysine crosslink that is predominantly in the interstitium surrounding tubules and within the glomerulus. Staining is particularly strong around tubules where extensive vacuolation is observed. Such a vacuolation is characteristic (ArmanniEpstein) of the effect of severe and sustained hyperglycemia on the renal tubules (Rasch, 1988; Ziyadeh and Goldfarb, 1991). It has been attributed to the accumulation of lipids and glycogen within tubular cells (Rasch, 1988; Ziyadeh and Goldfarb, 1991). The distribution of the $\epsilon$-( $\gamma$-glutamyl)-lysine crosslink follows a pattern comparable to that of the Masson's trichrome staining and correlated closely with the immunostaining pattern for interstitial type IV collagen described previously (Park et al, 1997). The increased extracellular $\epsilon$-( $\gamma$-glutamyl)-lysine crosslink was not associated with a parallel increase in total renal Tg; however, Tg was specifically increased within the diabetic glomeruli as demonstrated by assays on isolated glomeruli. In the tubulointerstitium, the increase in $\epsilon$-( $\gamma$-glutamyl)-lysine was solely associated with a translocation of $\mathrm{tTg}$ from an intracellular to extracellular pool. This externalization of tTg would facilitate its activation due to the presence of a high $\mathrm{Ca}^{2+}$ concentration and an absence of regulating GTP outside the cell. This is supported by the fact that $\mathrm{Tg}$ activity was predominantly extracellular and that $\mathrm{tTg}$ and $\epsilon$-( $\gamma$-glutamyl)-lysine crosslink appear to colocalize in the same extracellular areas within the tubulointerstitium and glomerular mesangium.

In glomeruli, the increased $\epsilon$-( $\gamma$-glutamyl)-lysine was associated with increased $\mathrm{Tg}$ and then further with increased levels of tTg. Although it is difficult by immunofluorescence to locate staining within the glomeruli accurately, both the $\epsilon$-( $\gamma$-glutamyl)-lysine and insoluble tTg stains are consistent with a pattern that would reflect staining of the GBM. Thus, in glomeruli, there is a synthesis-dependent translocation of tTg to the extracellular environment. Moreover, given the extracellular location of $\epsilon$-( $\gamma$-glutamyl)-lysine, the observed increase in the ratio of $\epsilon$-( $\gamma$-glutamyl)-lysine to hydroxyproline (collagen) has important implications. For the first time in an in vivo situation we have described an increase in the number of $\epsilon$-( $\gamma$-glutamyl)lysine crosslinks per collagen molecule. This demonstrates a qualitative change in the ECM. This suggests that formation of the $\epsilon$-( $\gamma$-glutamyl)-lysine crosslink in the diseased kidney is in addition to, rather than concomitant with increases in ECM accumulation. This strengthens the claim that $\mathrm{tTg}$ is a potential therapeutic target for modulating renal fibrosis.

Given the potential damage caused by hyperglycemia in both the glomerulus and mesangium (Mauer et al, 1984; Rasch, 1988; Ziyadeh and Goldfarb, 1991), the changes in $\epsilon$-( $\gamma$-glutamyl)-lysine and tTg location would be consistent with the suggested role of tTg as a stress-related enzyme involved in tissue repair ( $\mathrm{Ha}-$ roon et al, 1999; Mirza et al, 1997; Raghunath et al, 1996). However, previous studies have reported increased tTg levels accompanying externalization (Johnson et al, 1997, 1999) rather than just the redistribution of enzyme observed in the tubulointerstitium, an observation comparable to one we find in the glomerulus. It remains a possibility that the increased presence of $\mathrm{tTg}$ in the ECM and the ability of the enzyme to crosslink itself into the ECM, making it a difficult protein to extract, may explain the marginally lower levels of detectable enzyme in the diabetic kidney. However, this could equally represent a genuine down-regulation of renal $\mathrm{Tg}$ within tubular cells, possibly in an attempt to minimize its release. With the expanding knowledge of the extracellular role of tTg and its functional association with membrane signaling proteins such as integrins, a mechanism could be postulated whereby extracellular tTg could regulate its own transcription by means of a negative feedback loop (Aeschlimann and Thomazy 2000).

Previous in vitro transfection studies have shown that increased intracellular expression of $\mathrm{tTg}$ also leads to increased externalization (Gaudry et al, 1999a, 1999b; Verderio et al, 1998). This is in keeping with the increased externalization of the enzyme seen in the ablation model of renal scarring (Johnson et al, 1999), which was consistent with higher enzyme levels. In this diabetic model, overall increases in renal tTg do not occur. Subsequently, in the tubules, the mechanism by which tTg is released and the trigger behind its increased translocation becomes a key issue in any pathological role tTg may have. Changes 

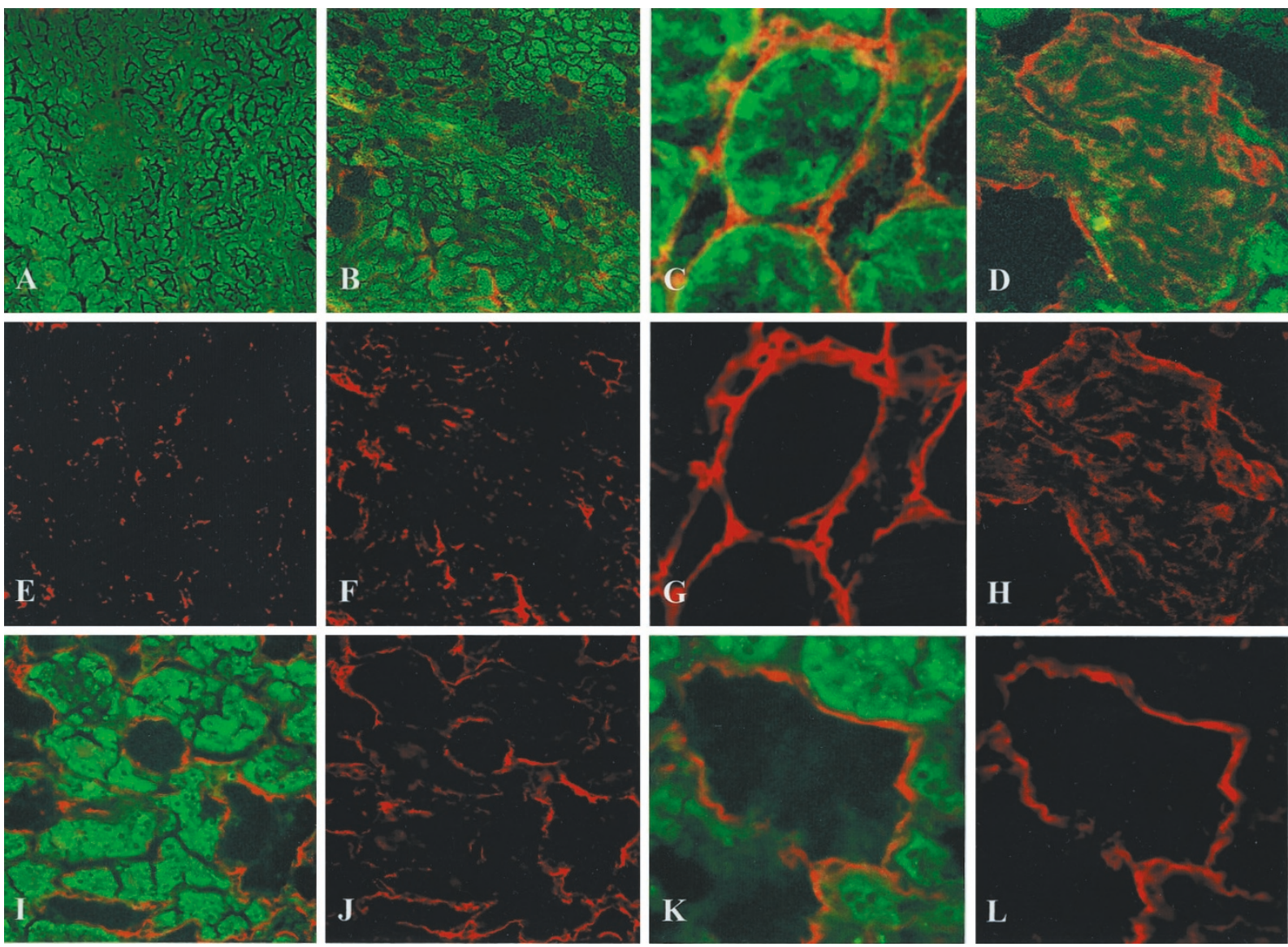

Figure 7.

Representative sections from 120-day control ( $A$ and $E$ ) and hyperglycemic kidneys ( $B$ to $D$ and $F$ to $L$ ) immunoprobed for tTg. $A$ to $D, I$ and $K$, autofluorescence at $530 \mathrm{~nm}$ (green) and Cy5 fluorochrome at $665 \mathrm{~nm}$ (red). E to H, J and L, Cy5 fluorochrome only. A, B, E, and F, original magnification $\times 100$; I and J, original magnification $\times 200 ; C, D, G, H, K$, and $L$, original magnification $\times 400$.

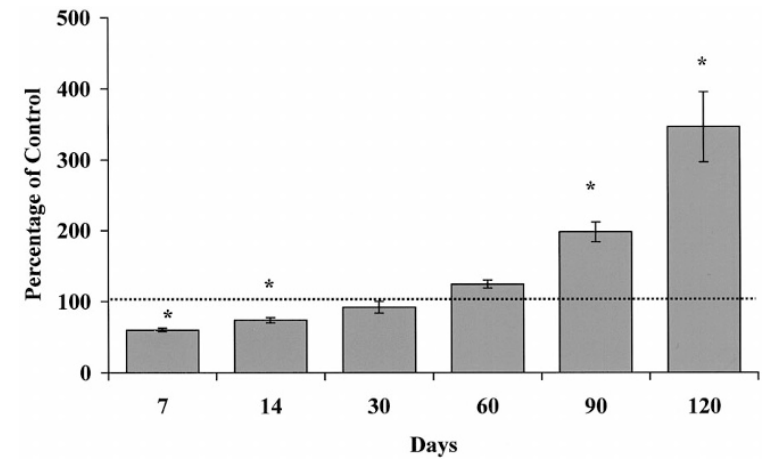

Figure 8.

Semiquantitation of Cy5 emissions at $665 \mathrm{~nm}$ from cryostat sections immunoprobed for tTg. Values are expressed as emissions from hyperglycemic renal cryostat sections as a percentage of time-matched control mean. $n=$ 4-6 per group, ${ }^{*}$ indicates $p<0.05$. At least 10 fields per section were analyzed.

in cell membrane permeability or integrity may occur due to low insulin or hyperglycemia (Mauer et al, 1984; Rasch, 1988; Ziyadeh and Goldfarb, 1991), resulting in leakage of the enzyme from damaged and/or stressed tubular epithelial cells (Upchurch et al, 1987; Verderio et al, 1998). Previous studies on remnant kidneys indicated that a number of tubular cells displayed high levels of $\epsilon$-( $\gamma$-glutamyl) lysine crosslink, suggesting that activation of the enzyme as a consequence of $\mathrm{Ca}^{2+}$ influx had occurred, perhaps due to this type of cellular stress. Unregulated release of $\mathrm{tTg}$ into the ECM by a non-golgi/ER secretion mechanism is possible, given evidence obtained from cell culture (Gaudry et al, 1999a; Verderio et al, 1998) and more recently from transgenic mice overexpressing $\mathrm{tTg}$ in the heart (Small et al, 1999), since the enzyme has no leader sequence or evidence of glycosylation (Gaudry et al,1999a, 1999b; Gentile et al, 1991; Lorand et al, 1988). In the diabetic kidney this is probably via the basal membrane of renal tubular cells, suggesting some type of control mechanism that might be responsive to cell stress or injury, or by the mosaic of growth factors generated in the kidney after hyperglycemia. This is of particular relevance in diabetic kidneys because tubular cells exposed to hyperglycemia are known to synthesize and release TGF- $\beta 1$ (Hoffman et al, 1998), a known stimulator of tTg (Douthwaite et al, 1999). tTg is, in turn, an activator of matrix-bound TGF- $\beta 1$ (Nunes et al, 1997), thus initiating potentially harmful positive feedback loops. Such a mechanism could also be linked to changes in secretion of other extracellular components in a tissue remodeling response. We have recently reported that $\mathrm{tTg}$ requires 
Table 2. Changes in tTg and $\varepsilon\left(\gamma\right.$-Glutamyl) Lysine in Glomeruli Isolated from Normal and Diabetic Kidneys ${ }^{a}$

\begin{tabular}{lccc}
\hline & $\begin{array}{c}\text { Control } \\
(n=4)\end{array}$ & $\begin{array}{c}\text { Diabetic } \\
(n=4-6)\end{array}$ & \\
\hline$\varepsilon(\gamma$-glutamyl) lysine \\
$\begin{array}{c}\text { (nmol/mg protein) } \\
\mathrm{Tg} \text { (activity assay) } \\
\quad \text { (units/mg protein) } \\
\mathrm{tTg} \text { antigen (Western blot analysis) } \\
\quad \text { (optical density units) }\end{array}$ & $0.18 \pm 0.07$ & $0.65 \pm 0.08$ & $p<0.05$ \\
$\begin{array}{c}\text { Hydroxyproline } \\
\quad(\text { nmol/mg protein) }\end{array}$ & $0.28 \pm 0.11$ & $0.64 \pm 0.07$ & $p<0.05$ \\
$\begin{array}{c}\text { Ratio of } \varepsilon(\gamma \text {-glutamyl) lysine: } \\
\text { hydroxyproline }\end{array}$ & $42.5 \pm 12.9$ & $97.2 \pm 23.9$ & $p<0.05$ \\
\hline
\end{tabular}

${ }^{a} 120$ days after STZ injection. Data represent mean values \pm SEM.

an intact fibronectin binding site for it to achieve its cell surface localization (Gaudry et al, 1999a). We have also demonstrated a close association of tTg and fibronectin with the latent TGF- $\beta 1$ binding protein at the surface of cells (Verderio et al, 1999). Changes in fibronectin secretion and deposition, therefore, could be important in determining the extracellular localization of the enzyme, which, in turn, is coupled to the storage and activation of TGF- $\beta 1$ in the diseased kidney, especially because an increase in renal fibronectin content is a key feature of progressive DN (Murphy et al, 1999).

In previous studies on experimental renal scarring using a rat subtotal nephrectomy model, we have failed to show changes in glomerular tTg or crosslink, concluding that there was either a failure to visualize due to glomerular structure or that there were distinct scarring mechanisms relating to tTg in the glomerular and tubulointerstitial compartments. This study indicates the latter to be true and serves to highlight the difference between different pathologies that ultimately lead to renal scarring. In DN, mesangium expansion and GBM thickening typically precedes tubular and interstitial involvement. However, in the rat STZ model there is conflicting evidence as to which pathology occurs first (Brito et al, 1998). Such changes may be brought about by early tTg-mediated cross-linking of the ECM, as we demonstrate in the glomeruli, making collagen or other potential substrates more resistant to breakdown during turnover (Johnson et al, 1999). This may explain some of the discrepancies in the literature whereby the increased mesangial expansion is not always associated with a detectable increase in the synthesis of ECM (Poulsom et al, 1988).

In common with our previous studies in the subtotal nephrectomy model of renal scarring (Johnson et al, 1997, 1999), there is an increase in tTg crosslink product within diabetic kidneys that potentially has significant biochemical effects on ECM regulation and turnover, either directly (Johnson et al, 1999) or via TGF- $\beta 1$ activation (Nunes et al, 1997). It is quite conceivable that $\mathrm{tTg}$ can cause excess deposition of ECM components because it has been shown in vitro to cause fibril formation in the absence of lysyl oxidase
(Kleman et al, 1995; Johnson et al, 1999), and when overexpressed in fibroblasts causes increased deposition of fibronectin and latent TGF- $\beta 1$ (Verderio et al, 1999). Moreover, we have previously shown in vitro that $\mathrm{tTg}$ cross-linking can interfere with matrix metalloproteinase action on collagen fibril formation, stabilizing the collagen fibril to degradation (Johnson et al, 1999). This is not surprising because the $\epsilon-(\gamma-$ glutamyl)-lysine crosslink is only removed from proteins by the cleavage of both the carboxyl and amino ends of glutamine and lysine and the site of MMP action is highly specific. In this study we have demonstrated that in the glomeruli, increased collagen deposition is further accompanied by an increased ratio of crosslink to collagen molecule. It has been suggested that with collagen $\mathrm{V}$ and $\mathrm{XI}$, tTg crosslinking occurred within the $\mathrm{N}$ and $\mathrm{C}$ termini of the collagen molecule (Kleman et al, 1995). Interestingly, this is the same region of the molecule that most MMP initially cleave (Imper and Van Wart, 1998). Thus, cross-linking here could prevent fibril collapse and subsequent degradation. $\mathrm{tTg}$ cross-linking within the ECM may therefore not only cause inappropriate and excessive ECM deposition, but also interfere with its turnover. Both these actions would lead to accumulation and scarring.

This study provides convincing evidence that there are large changes in renal $\epsilon$-( $\gamma$-glutamyl) lysine in the extracellular environment that may lead to ECM accumulation in DN. This results from the cellular release of tTg in the hyperglycemic kidney. These changes are consistent with the pathologic changes observed in human disease that lead to progressive loss in renal function. tTg may therefore be a key molecule in the damage response mechanism observed in DN, ultimately contributing to its progression.

\section{Materials and Methods}

\section{Experimental Animals and Protocol}

Male Wistar rats (Sheffield University strain) of approximately similar weight (350 to $400 \mathrm{~g}$ ) and age (8 to 10 weeks) were subjected to STZ-induced DM $(45 \mathrm{mg} / \mathrm{kg}$ in citrate buffer, $\mathrm{pH} 4.0$ ) or vehicle alone, as previously 
described (Arison et al, 1967). A serum glucose level above $15 \mathrm{mmol} / \mathrm{l}$ at 48 hours after STZ injection was considered diabetic. At 7, 15, 30, 60, 90, and 120 days after injection, rats were killed and the kidneys removed from both STZ $(n \geq 5)$ and control $(n \geq 4)$ groups. Before they were killed, all rats had their serum creatinine and proteinuria measured. Creatinine was measured by standard autoanalyzer technique and proteinuria by the Biuret method. Rats were housed 2 to 4 to a cage and maintained at $20^{\circ} \mathrm{C}$ and $45 \%$ humidity on a 12-hour light/dark cycle. They were allowed free access to standard rat chow (Labsure, Cambridge, United Kingdom) and tap water. All procedures were carried out under license according to regulations laid down by Her Majesty's Government, United Kingdom (Animals Scientific Procedures Act, 1986).

\section{Quantitative Assessment of Renal Scarring}

The extent of mesangial and tubulointerstitial expansion after the induction of DM was determined by two of the authors (MF and MJ) blinded to the experimental code, using a morphometric analysis based on point counting (Johnson et al, 1997). For this, dewaxed sections stained with Masson's trichrome stain were used. Transverse sections of the kidney, which passed through the papilla, were selected. The sections were viewed down a light microscope with a $\times 40$ (glomerular) or $\times 20$ (tubulointerstitium) flat field objective. A square lattice of 64 or 25 points (for glomerular and tubulointerstitial counting, respectively) with a surface area of $0.016 \mathrm{~mm}^{2}$ was superimposed onto the tissue via a drawing tube. Data were collected from a minimum of 25 glomeruli or a series of adjacent fields extending perpendicularly from the cortex to the junction between the outer and the inner stripes of the outer medulla. Three such linear series of 9 to 12 fields were measured per section and two stained sections per kidney were analyzed. The proportion of points falling on stained structures was estimated in relation to the total number of points counted.

\section{Measurements of Renal $\epsilon-(\gamma$-Glutamyl)-Lysine Dipeptide}

This was performed as previously described (Griffin and Wilson, 1984). Approximately $10 \mathrm{mg}$ of protein was precipitated from a $20 \%(\mathrm{w} / \mathrm{v})$ tissue homogenate by adding trichloroacetic acid (TCA) to a final concentration of $10 \%(\mathrm{w} / \mathrm{v})$. After rehydration in $0.1 \mathrm{M}$ ammonium carbonate, extracted proteins were subjected to exhaustive proteolytic digestion with subtilisin (EC 3.4.21.61), pronase (EC 3.4.24.31), activated leucine amino peptidase (EC 3.4.11.2), activated prolidase (EC 3.4.14.9), and carboxypeptidase Y (EC 3.4.16.1). Samples were then freeze-dried and resuspended in $0.1 \mathrm{~N} \mathrm{HCl}$ and stored at $-20^{\circ} \mathrm{C}$. The amount of $\epsilon$-( $\gamma$-glutamyl)-lysine in the tissue digests was analyzed by cation exchange chromatography using an LKB 4151 amino acid analyzer (Pharmacia, Cambridge, United Kingdom) by a modification of a lithium citrate buffer method (Griffin and Wilson, 1984). Sep- aration of $\epsilon$-( $\gamma$-glutamyl)-lysine dipeptide was achieved using Ultrapac 8 cation exchange resin $(8 \pm$ $0.5 \mu \mathrm{m}$ particle size) at a constant temperature of $25^{\circ} \mathrm{C}$ and stepwise gradient of increasing molarity and $\mathrm{pH}$ of lithium citrate buffers. The detection of amino acids and peptides was via a post-column reaction with o-phthalaldehyde, $\beta$ mercaptoethanol and the fluorescence was observed at $450 \mathrm{~nm}$ after excitation at $360 \mathrm{~nm}$ (LS1; Perkin Elmer, Beaconsfield, United Kingdom). Quantitation was achieved by computer integration of the chromatograms obtained using a Nelson 9000 A-D integrator and software (Perkin Elmer, Cupertino, California). The amount of $\epsilon-(\gamma-$ glutamyl)-lysine in each sample was quantified by standard addition of $\epsilon$-( $\gamma$-glutamyl)-lysine dipeptide.

To confirm the validity of the analysis, approximately $30 \%$ of the samples were reanalyzed by reverse phase HPLC using $\sigma$-phthalaldehyde as a precolumn derivitizing agent as previously documented by Griffin and Wilson (1984). Before analysis, samples were prepurified using cation exchange chromatography (Coppola et al, 1989).

\section{Measurement of Renal Tg}

Renal Tg levels were measured using a ${ }^{14} \mathrm{C}$-putrescine incorporation assay. Twenty percent of the homogenates were incubated with $10 \mathrm{~mm} \mathrm{Ca}^{2+}$ to activate all available $\mathrm{Tg}$, and the level of enzyme was determined by the incorporation of $\left[1,4-{ }^{14} \mathrm{C}\right]$ putrescine into N,N'dimethylcasein as described previously (Lorand et al, 1972). Results are corrected to units per milligram protein (1 unit $=1 \mathrm{nmol}$ putrescine incorporated per hour at $\left.37^{\circ} \mathrm{C}\right)$.

\section{Measurements of Renal tTg Antigen}

Levels of tTg antigen were determined by immunoprobing of Western blots. Fifteen micrograms of protein was separated on $10 \%(\mathrm{w} / \mathrm{v})$ polyacrylamide gels and then electroblotted on to ECL nitrocellulose membranes (Amersham Scientific, Little Chalfont, Buckinghamshire, United Kingdom). The Western blot was then immunoprobed with $0.2 \mu \mathrm{g} / \mathrm{ml}$ of a monoclonal mouse anti-tTg antibody (TG100; Stratech Scientific, Luton, United Kingdom) at $4^{\circ} \mathrm{C}$. Primary antibody binding was revealed with $1.5 \mu \mathrm{g} / \mathrm{ml}$ goat antimouse HRP secondary antibody (DAKO, Ely, Cambridgeshire, United Kingdom) for 1 hour at room temperature, followed by enhanced Western blotting chemiluminescence (Amersham). Kodak AR autoradiograph films were exposed for the required time and developed with Kodak GBX developer and fixer. Films were quantitated by volume densitometry using a Bio Rad GS-690 imaging densitometer and molecular analyst version 4 software (Bio-Rad, Hertfordshire, United Kingdom). Determination of band size was by reference to Kaleidoscope protein markers (Bio-Rad) using the same analysis package. 


\section{Localization of $t T g$ and $\epsilon-(\gamma-$ Glutamyl)-Lysine}

To prevent tTg antibody occlusion, all immunohistochemistry was undertaken on unfixed cryostat sections. To prevent false localization it is essential to remove soluble $\mathrm{Tg}$; this technique, therefore, only localizes insoluble (substrate-bound tTg) (Johnson et al, 1999).

Kidney tissue was snap frozen in liquid nitrogen and then mounted in OCT mounting media (Raymond Lamb, Eastbourne, Sussex, United Kingdom). Cryostat sections, $10 \mu \mathrm{m}$ thick, were cut at $-12^{\circ} \mathrm{C}$ and placed onto BDH GOLD glass slides (BDH Laboratory Supplies, Poole, United Kingdom) and stored at $-20^{\circ} \mathrm{C}$ before use.

All solutions before fixation were supplemented with the protease inhibitors $1 \mathrm{~mm}$ leupeptin, $1 \mathrm{~mm}$ benzamidine, $1 \mathrm{~mm}$ pepstatin, $1 \mathrm{~mm}$ PMSF, and $10 \mathrm{~mm}$ EDTA. Sections were thawed, washed to remove soluble tTg, and then blocked for 1 hour at room temperature in antibody dilution buffer (3\% bovine serum albumin, $0.01 \%$ Triton $\times 100$ in PBS at $\mathrm{pH} 7.4$ ) to which was added $5 \%(\mathrm{v} / \mathrm{v})$ goat serum. Sections were then washed with PBS, and either a 1:300 dilution of a monoclonal anti-tTg antibody (CUB7042) (Stratech Scientific), a 1:500 dilution of a monoclonal $\epsilon-(\gamma$-glutamyl) lysine antibody (81-D4; Covalabs, Lyon, France), or mouse nonimmune serum (DAKO) was applied to the sections and incubated overnight at $4^{\circ} \mathrm{C}$. Sections were washed with PBS and then fixed with cold methanol $\left(-20^{\circ} \mathrm{C}\right)$ for 10 minutes. These were then washed in PBS before addition of a 1:500 dilution of a goat antimouse Cy5 (indodicarbocyanine) conjugated antibody (Stratech Scientific) and incubation for 1 hour at room temperature. Sections were then washed in PBS and mounted with vector shield fluorescent mounting media (Vector Laboratories, Peterborough, United Kingdom).

Sections were visualized using a Leica TCS NT confocal microscope (Leica, Wetzlar, Germany) using a Kr/AR laser (647 nm and $488 \mathrm{~nm}$ ) for both Cy5 (optimal excitation $650 \mathrm{~nm}$ ) and auto fluorescence. Computer imaging and analyses were obtained at 665 $\mathrm{nm}$ and $530 \mathrm{~nm}$ for Cy5 and autofluorescence, respectively (Leica TCS NT Lasertechnik; Leica). Semiquantitation of staining on each slide was obtained using the mean Cy5 emissions per field $\left(\mathrm{mV} / \mu \mathrm{m}^{2}\right)$ from at least ten $200 \times$ magnification fields.

\section{In Situ Tg Activity}

The determination of in situ Tg activity was as previously described (Johnson et al, 1999). Briefly, cryostat sections were incubated with fluorescein (FITC) cadaverine (Molecular Probes, Leiden, The Netherlands) and $\mathrm{CaCl}_{2}$. Negative controls included the replacement of $\mathrm{CaCl}_{2}$ with EDTA or the addition of cystamine (Tg inhibitor) or CUB7042 (tTg-inactivating antibody) (Stratech Scientific). After washing, fixing, and blocking, incorporated fluorescein cadaverine was revealed by immunoprobing with a mouse anti-FITC monoclonal antibody and visualized with a goat antimouse Cy5 (indodicarbocyanine) conjugated antibody (Stratech Scientific). Sections were visualized using confocal microscopy (Leica) using a $\mathrm{Kr} / \mathrm{Ar}$ laser for both Cy5 (optimal excitation $650 \mathrm{~nm}$ ) and FITC (optimum excitation $467 \mathrm{~nm}$ ). Computer imaging and analyses were obtained at emission wavelengths of $655 \mathrm{~nm}$ and 530 $\mathrm{nm}$ for Cy5 and FITC, respectively. Semiquantitation of activity on each slide was obtained using the mean Cy5 emissions per field $\left(\mathrm{mV} / \mu \mathrm{m}^{2}\right)$ from at least ten $200 \times$ magnification fields.

\section{Isolation of Glomeruli and Measurements}

Glomeruli were isolated by conventional size selective sieving (Doi et al, 1989). Immediately after removal the kidney was finely chopped and then forced through $425 \mu \mathrm{m}$ and $180 \mu \mathrm{m}$ mesh stainless steel sieves using a smooth bottomed conical flask and copious volumes of ice-cold $10 \mathrm{~mm}$ EDTA in PBS. Glomeruli passing through were collected on a $53 \mu \mathrm{m}$ mesh sieve below. While still on the $53 \mu \mathrm{m}$ sieve, glomeruli were washed extensively with ice-cold $10 \mathrm{~mm}$ EDTA in PBS before being transferred to a sterile capped centrifuge tube and centrifuged at $7 \times g$ for 5 minutes. The supernatant was removed and replaced with fresh PBS. A small aliquot was removed and viewed by light microscopy to check both the purity and integrity of isolated glomeruli. The remaining glomeruli were freeze-dried and stored at $-70^{\circ} \mathrm{C}$ until analysis. Analysis for Tg, tTg, and $\epsilon-(\gamma$-glutamyl) lysine was essentially as described above.

\section{Hydroxyproline Quantitation in Isolated Glomeruli}

Collagen content was assessed by measuring hydroxyproline levels in proteins by RP-HPLC (Campa et al, 1990). Isolated glomeruli were hydrolyzed in 6 $\mathrm{M} \mathrm{HCL}$ at $110^{\circ} \mathrm{C}$ overnight, dried by centrifugal evaporation and resuspended in water. Hydroxyproline was isolated and measured by RP-HPLC after derivatization with 7-chloro-4-nitrobenz-2-oxa-1,3diazole (NBD-Cl).

\section{Data Analysis}

All data were averaged and the standard error calculated. Experimental groups were compared using Student's $t$ test with unequal variance. $p<0.05$ was taken as statistically significant.

\section{Acknowledgements}

The authors would like to thank predominantly the British Diabetic Association, but also the Sheffield Kidney Research Foundation, the Sheffield Area Kidney Association, the Nottingham Trent University, and the Northern General Hospital NHS Trust Research Committee, for their financial support of this study.

\section{References}

Aeschlimann D and Paulsson M (1991). Crosslinking of laminin-nidogen complexes by tissue transglutaminase: $\mathrm{A}$ 
novel mechanism for basement membrane stabilization. J Biol Chem 266:15308-15317.

Aeschlimann D and Thomazy V (2000). Protein crosslinking in assembly and remodelling of extracellular Matrices: The role of transglutaminases. Connect Tissue Res 41:1-27.

Alberti KG and Zimmet PZ (1998). Definition, diagnosis and classification of diabetes mellitus and its complications. Diabet Med 15:539-553.

Amos AF, McCarty DJ, and Zimmet $P$ (1998). The rising global burden of diabetes and its complications: Estimates and projections to the year 2010. Diabet Med 14:S1-S84.

Arison RN, Ciaccio EL, and Glitzer MS (1967). Light and electron microscopy of lesions in rats rendered diabetic with streptozotocin. Diabetes 16:51-56.

Bowness JM, Folk JE, and Timpl R (1987). Identification of a substrate for liver transglutaminase on the aminopropeptide of type III collagen. J Biol Chem 262:1022-1024.

Brito PL, Fioretto P, Drummond K, Kim Y, Steffes MW, Basgen JM, Sissons-Ross S, and Maurer M (1998). Proximal tubular basement membrane width in insulin-dependent diabetes mellitus. Kidney Int 53:754-761.

Campa JS, McAnulty RJ, and Laurent GJ (1990). Application of high performance liquid chromatography to studies of collagen production by isolated cells in culture. Biochemistry 186:257-263.

Coppola G, Underwood J, Cartwright G, and Hearn MTW (1989). High performance liquid chromatography of amino acids, peptides and proteins. J Chromatogr 476:269-290.

Defronzo RA (1995). Diabetic nephropathy: Etiologic and therapeutic consideration. Diabetes Rev 3:510-564.

Doi T, Striker L-J, Elliot S-J, Conti F-G, and Sriker G-E (1989). Insulin like growth factor 1 is a progression factor for human mesangial cells. Am J Path 134:395-404.

Douthwaite JA, Johnson TS, Haylor JL, and EI Nahas AM (1999). Effects of transforming growth factor- $\beta 1$ on renal extra-cellular matrix components and their regulating proteins. J Am Soc Nephrol 10:2109-2119.

Dudek SM and Johnson GV (1993). Transglutaminase catalyses the formation of sodium dodecyl sulfate-insoluble, Alz50-reactive polymers of tau. J Neurochem 61:1159-1162.

Fesus L, Thomazy F, Autuori MP, Ceru MP, Tarcsa E, and Piacentini M (1989). Apoptotic hepatocytes become insoluble in detergents and chaotropic agents as a result of transglutaminase action. FEBS Lett 245:150-154.

Folk JE and Finlayson JE (1977). The $\epsilon$-( $\gamma$-glutamyl)-lysine crosslink and the catalytic role of transglutaminase. Adv Protein Chem 31:1-133.

Fukui M, Nakamura T, Ebihara I, Shirato I, Tomino Y, and Koide $H$ (1992). ECM gene expression and its modulation by insulin in diabetic rats. Diabetes 41:1520-1527.

Gaudry CA, Verderio E, Aeschlimann D, Cox A, Smith C, and Griffin M (1999a). Cell surface localisation of tissue transglutaminase is dependent on a fibronectin binding site in its $\mathrm{N}$-terminal $\beta$-sandwich domain. J Biol Chem 274:3070730714.

Gaudry CA, Verderio E, Jones RA, Smith C, and Griffin M (1999b). Tissue transglutaminase is an important player at the surface of human endothelial cells: Evidence for its external- isation and its co-localisation with the $\beta 1$ integrin. Exp Cell Res 252:104-113.

Gentile V, Saydak M, and Chiocca E (1991). Isolation and characterisation of cDNA clones to mouse macropharge and human endothelial cell tissue transglutaminase. J Biol Chem 266:478-483.

Griffin M and Smethurst PA (1996). Transglutaminase: Enzymes that crosslink proteins. Retinoids: Today and Tomorrow $37: 4-10$.

Griffin M, Smith L, and Wayne L (1979). Changes in transglutaminase activity in and experimental model of pulmonary fibrosis induced by parquet. Br J Exp Pathol 60:653-661.

Griffin $M$, and Verderio $E$ (2000). Tissue transglutaminase in cell death. In: Bryant JA, Hughes SG, and Galand JM, editors. Programmed cell death in animals and plants. London: Bios Scientific Publications, 223-238.

Griffin M and Wilson J (1984). Detection of epsilon-(gammaglutamyl)-lysine. Mol Cell Biochem 58:37-49.

Haroon ZA, Hettasch JM, Lai TS, Dewhirst MW, and Greenberg CS (1999). Tissue transglutaminase is expressed, active, and directly involved in rat derunal wound healing and angiogenesis. FASEB J 13:1787-1795.

Hoffman BB, Sharma K, and Ziyadeh FN (1998). The role of TGF $\beta$ in diabetic nephropathy. Miner Electrolyte Metabol 24:190-196.

Im MJ, Russell MA, and Feng JF (1997). Transglutaminase II: A new class of GTP-binding protein with new biological functions. Cell Signal 9:477-482.

Imper V and Van Wart HE (1998). Substrate specificity and mechanisms of substrate recognition of the matrix metalloproteinases. In: Parks WC and Mecham RP, editors. Matrix metalloproteinases. London: Academic Press, 219-238.

Johnson TS, Griffin M, Thomas GL, and El Nahas M (1997). The role of transglutaminase in the rat subtotal nephrectomy model of renal fibrosis. J Clin Invest 99:2950-2960.

Johnson TS, Scholfield Cl, Parry J, and Griffin M (1998). Induction of tissue transglutaminase by dexamethasone: Its correlation to receptor number and transglutaminase mediated cell death in a series of malignant hamster fibrosarcomas. Biochem J 331:105-112.

Johnson TS, Skill NJ, El Nahas AM, and Griffin M (1999). Transglutaminase transcription and antigen translocation in experimental renal scarring. J Am Soc Nephrol 10:21462157.

Kleman JP, Aeschlimann D, Paulson M, and Van derrest M (1995). Transglutaminase catalysed crosslinking of fibrils of collagen V/XI in A204 rhabdomyosarcoma cells. Biochemistry 34:13768-13775.

Knight CRL, Rees RC, and Griffin M (1991). Apoptosis: A potential role for cytosolic transglutaminase and its importance in tumour progression. Biochim Biophys Acta 1096: 312-318.

Krolewski AS, Warram JH, Christlieb AR, Busick EJ, and Kahn CR (1985). The changing natural history of nephropathy in type I diabetes. Am J Med 78:785-793.

Lorand L, Cambell-Wilkes LK, and Cooperstein L (1972). A filter paper assay for transamidating enzymes using radioactive amine substrates. Anal Biochem 50:623-631. 
Lorand L and Conrad SM (1984). Transglutaminases. Mol Cell Biochem 58:9-35.

Lorand L, Daily JE, and Turner PM (1988). Fibronectin as a carrier for the transglutaminase from human erythrocytes. Proc Natl Acad Sci USA 85:1057-1059.

Lupia E, Elliot SJ, and Lenz O (1999). IGF-1 decreases collagen degradation in diabetic NOD mesangial cells: Implications for diabetic nephropathy. Diabetes 48:1638-1644.

Mauer SM, Steffes E, Ellis N, Sutherland DER, Brown DM, and Goetz FC (1984). Structural-functional relationships in diabetic nephropathy. J Clin Invest 74:1143-1155.

Mirza A., Liu SL, Frizell E, Zhu J, Maddukuri S, Martinez J, Davies P, Schwarting R, Norton P, and Zern MA (1997). A role for tissue transglutaminase in hepatic injury and fibrogenesis, and its regulation by NFKB. Am J Physiol 272:G281-G288.

Molberg O, McAdam SN, and Sollid LM (2000). Role of tissue transglutaminase in celiac disease. J Pediatr Gastroenterol Nutr 30:232-240.

Murphy M, Godson C, Cannon S, Kato S, MacKenzie HS, Martin F, and Brady HR (1999). Suppression subtractive hybridization identifies high glucose levels as a stimulus for expression of connective tissue growth factor and other genes in human mesangial cells. J Biol Chem 274:58305834 .

Nunes I, Gleizes PE, Metz CN, and Rifkin DB (1997). Latent transforming growth factor binding protein domains involved in activation and transglutaminase-dependent crosslinking of latent transforming growth factor Beta. J Cell Biol 136:11511163.

Park I, Kiyomoto H, Abboud S, and Abboud H (1997). Expression of transforming growth factor beta and type IV collagen in early streptozotocin induced diabetes. Diabetes 46:473-480.

Phillips AO, Janssen U, and Floege J (1999). Progression of diabetic nephropathy: Insights from cell culture and animal models. Kidney Blood Press Res 22:81-97.

Poulsom R, Kurkinen M, Prockop DJ, and Boothandford RP (1988). Increased steady state levels of Laminin $\beta 1$ in kidneys of long term streptozotocin-diabetic rats: No effect of aldose reductase inhibitor. J Biol Chem 263:10072-10076.
Raghunath M, Höpfner B, Aeschlimann D, Lüthi U, Meuli M, Altermatt S, Gobet R, Bruckner-Tuderman L, and Steinmann B (1996). Crosslinking of the dermo-epidermal junction of skin regenerating from keratinocyte autografts. J Clin Invest 98:1174-1184.

Rasch R (1988). Non-glomerular lesions in the diabetic kidney (Proceedings of the Tenth International Congress of Nephrology). Nephrology 1:744-760.

Small K, Feng JF and Lorenz J (1999). Cardiac specific over expression of transglutaminase II (Gh) results in a unique hyperthrophy phenotype independent of phospholipase activation. J Biol Chem 274:21296-21299.

Suzuki D, Miyazaki M, and Jinde K (1997). In situ hybridisation studies of matrix metalloproteinasde-3, tissue inhibitor of metalloproteinase-1 and type IV collagen in diabetic nephropathy. Kidney Int 52:111-119.

Upchurch HF, Conway E, Patterson MK, Birkbichler PJ, and Maxwell MD (1987). Cellular transglutaminase has affinity for extracellular matrix. In Vitro Cell Develop Biol 23:795-800.

Verderio E, Gaudry C, Gross S, Smith C, Downes S, and Griffin M (1999). Regulation of cell surface tissue transglutaminase: Effects of matrix storage of latent transforming growth factor $\beta$ binding protein 1. J Histochem Cytochem 47:1417-1432.

Verderio E, Nicholas B, Gross S, and Griffin M (1998). Regulated expression of tissue transglutaminase in Swiss 3T3 fibroblasts: Effects on the processing of fibronectin cell attachment and cell death. Expt Cell Res 239:119-138.

Wayl P, Deppermann D, and Hasslacher C (1982). Biochemistry of glomerular basement membrane of the normal and diabetic human. Kid Int 21:744-749.

Ziyadeh FN and Goldfarb S (1991). The renal tubulointerstitium in diabetes mellitus. Kidney Int 39:464-475. 